\title{
Cancer Antigen 72-4 Measurement
}

National Cancer Institute

\section{Source}

National Cancer Institute. Cancer Antigen 72-4 Measurement. NCI Thesaurus. Code C106505.

The determination of the amount of the cancer antigen 72-4 present in a sample. 